\title{
Total versus staged versus functional revascularization in NSTEACS patients with multivessel disease
}

\author{
Ahmed O. Elkady ${ }^{1}$, Mohamed Abdelghany², Reda Diab², Ahmed Ezz ${ }^{1}$ and Abdalla A. Elagha2 ${ }^{2 *}$
}

\begin{abstract}
Background: The optimal strategy for revascularization in patients with NSTEACS who had multivessel coronary artery disease. A lack of evidence exists about the role of complete coronary revascularization by $\mathrm{PCl}$ in patients with non-ST segment elevation acute coronary syndrome (NSTEACS). Till now, ACC/AHA and ESC guidelines are not clear regarding the optimal strategy for revascularization in NSTEACS patients with multivessel coronary artery disease. In this setting, identification of the culprit lesion by angiography only could be challenging. The objective is to compare the hospital and short-term (6 months) outcomes of 3 different coronary revascularization strategies in NSTEACS patients with and multivessel coronary artery disease.

Results: Our study was a prospective study that included 90 patients who presented with acute chest pain and were diagnosed with NSTEACS. The patients were divided into 3 groups according to the plan of management: total revascularization group (total group), staged revascularization group (staged group), and functional revascularization group using FFR (FFR group). We studied the effect of demographic data, risk factors, and angiographic and procedural criteria on hospital and short-term outcomes. No significant statistical difference was seen among the three groups regarding the hospital outcome (in-stent thrombosis, unstable angina, and renal impairment). Also, the short-term (after 6 months) outcome regarding myocardial infarction, hospitalization, stroke, and cardiac death did not differ significantly between the three groups.

Conclusions: Considering NSTEACS patients with multivessel disease, different coronary revascularization strategies (total, staged, or FFR) are comparable regarding immediate and short-term (6 months) clinical follow-up. FFR can change the preplanned management, and less number of stents per patient is needed when FFR is utilized.
\end{abstract}

Keywords: Non-ST segment elevation acute coronary syndrome (NSTEACS), Acute coronary syndrome (ACS), Fractional flow reserve (FFR)

\section{Background}

Visual assessment of the severity of coronary artery disease in non-ST segment elevation acute coronary syndrome (NSTEACS) patients is usually the guide that directs the management decision either medical treatment, percutaneous coronary intervention (PCI), or coronary artery bypass surgery (CABG) $[1,2]$. This

\footnotetext{
* Correspondence: abdalla.elagha@kasralainy.edu.eg; abdallaaa@yahoo.com ${ }^{2}$ Cardiovascular Department, Kasr-Alainy Hospital, Cairo University, 1 Saraya St., Third Floor, Manial, Cairo, Egypt

Full list of author information is available at the end of the article
}

assessment of lesion severity utilizing coronary angiography by cardiologists may be inaccurate resulting in under- or overestimation of the physiological significance of the lesion. Frankly speaking, judgments made by interventional cardiologists in everyday practice are frequently subjective and potentially can lead to misdiagnosis and incorrect management strategy [3, 4]. Identification of the culprit lesion in the setting of NSTEACS by angiography alone could be challenging. Secondary plaque ruptures in patients with ACS are frequent (about 25\%) as suggested by histopathological, intravascular ultrasound, and optical

\section{Springer Open}

(- The Author(s). 2021 Open Access This article is licensed under a Creative Commons Attribution 4.0 International License, which permits use, sharing, adaptation, distribution and reproduction in any medium or format, as long as you give appropriate credit to the original author(s) and the source, provide a link to the Creative Commons licence, and indicate if changes were made. The images or other third party material in this article are included in the article's Creative Commons licence, unless indicated otherwise in a credit line to the material. If material is not included in the article's Creative Commons licence and your intended use is not permitted by statutory regulation or exceeds the permitted use, you will need to obtain permission directly from the copyright holder. To view a copy of this licence, visit http://creativecommons.org/licenses/by/4.0/. 
coherence tomography analysis. A benefit for multivessel PCI in patients with STEMI and multivessel disease has been suggested by multiple randomized trials $[5,6]$. On the other hand, the role of single versus staged PCI in NSTEACS was studied by only one dedicated trial [7].

To our knowledge, this is the first study to compare total versus staged versus functional coronary revascularization in NSTEACS patients.

\section{Methods}

\section{Patient selection}

This prospective study was conducted on 90 patients at the Kobry El-kobba Military Hospital during a 12-month period. The inclusion criteria were as follows: diagnosis of NSTEACS according to the ESC 2015 guidelines, coronary angiography showing multivessel disease, creatinine clearance $>60 \mathrm{ml} / \mathrm{min}$, planned early invasive strategy within $48 \mathrm{~h}$ from the presentation, and signed informed consent. The exclusion criteria were as follows: cardiogenic shock, chronic total occlusion, previous coronary artery bypass graft surgery, SYNTAX score $>32$, indication for bypass surgery (severe valvular disease, left main disease), patients with STEMI, previous history of anaphylactoid reaction to contrast media, acute renal failure or severe chronic non-dialysis-dependent kidney disease, and patients who refused to provide consent for study enrollment.

\section{Study design}

After coronary angiography was done and interpreted by at least two experienced interventional cardiologists, the patient was randomly assigned to one of the three management plans using "1:1:1 randomization method." The three management plans are as follows: (1) total revascularization (total group) in which all diseased coronaries would be completely revascularized during the index procedure, (2) staged revascularization (staged group) in which only the culprit artery would be revascularized during the index procedure followed by complete coronary revascularization of non-culprit lesions in another session within the following 6 weeks, and (3) functional revascularization (FFR group) in which revascularization would be performed only to the hemodynamically significant lesions determined by FFR.

The culprit vessel was determined using ECG, echocardiography, or/and angiography criteria. An FFR $\leq$ 0.80 is an evidence-based functional threshold that correlates with the presence of a hemodynamically significant lesion, while values $>0.80$ indicate that patients can be managed safely with medical therapy without the need for coronary stenting.

Procedural data (duration, contrast volume, complication, and success rate) were documented for each patient. Also, hospital course (duration of hospitalization, adverse events, and primary outcome) was obtained. Furthermore, short-term outcomes via office-based direct visits were performed at 1 and 6 months.

According to the presence or absence of elevated cardiac biomarkers, our patients were divided into the nonST elevation myocardial infarction (NSTEMI) group (patients who had elevated cardiac troponin) and unstable angina (UA) group (patients with normal troponin).

\section{Results}

Male gender was more prevalent in our study (74 male and 16 female patients). The mean age was $61.22 \pm 7.52$ years. All our patients presented with NSTEACS; 17 patients had signs of lung congestion. Fifty-five patients were found to be hypertensive, 61 patients were recorded as active smokers, 39 patients were diabetics, and 35 patients had a positive family history of premature coronary artery disease. Sixty-three patients were found to have dynamic ECG changes at the time of presentation. Twenty-six of our patients had positive troponin. Regarding echocardiography, the mean EF was $54.71 \% \pm 6.23 \%$.

\section{Procedure data and outcome}

The mean duration of the procedure was $41.08 \pm 13.75$ min, the mean volume of contrast used was $300.56 \pm$ $84.63 \mathrm{ml}$, and the mean value of the SYNTAX score was $11.31 \pm 3.03$. Regarding the outcome, nine of our patients suffered chest pain during the hospital stay, and they were all managed medically. Only one patient developed renal impairment, and no one developed instent thrombosis (manifested by ECG and cardiac enzyme abnormalities).

\section{Follow-up}

Eight patients were re-hospitalized, and 4 patients suffered cardiac death during the 6-month follow-up period (Fig. 1). No myocardial infarction or cerebrovascular events were encountered during the follow-up period (Table 1).

Comparison among the three groups: total revascularization (total group), staged revascularization (staged group), and functional revascularization (FFR group), was done regarding all the recorded data. The mean age was comparable among the 3 groups $(\mathrm{P}$ value $=\mathrm{NS})$. There was no statistically significant difference between the three groups regarding the clinical presentation of patients $(\mathrm{P}$ value $=0.356)$. The subjects of the three groups had comparable results regarding their associated risk factors (hypertension, diabetes, smoking, and positive family history of premature coronary artery disease). The distribution of dynamic ECG changes among the patients of the three groups was comparable $(\mathrm{P}$ value $=$ 0.263). Positive troponin was found in 8 patients in both the total and the FFR groups and 10 patients in the 


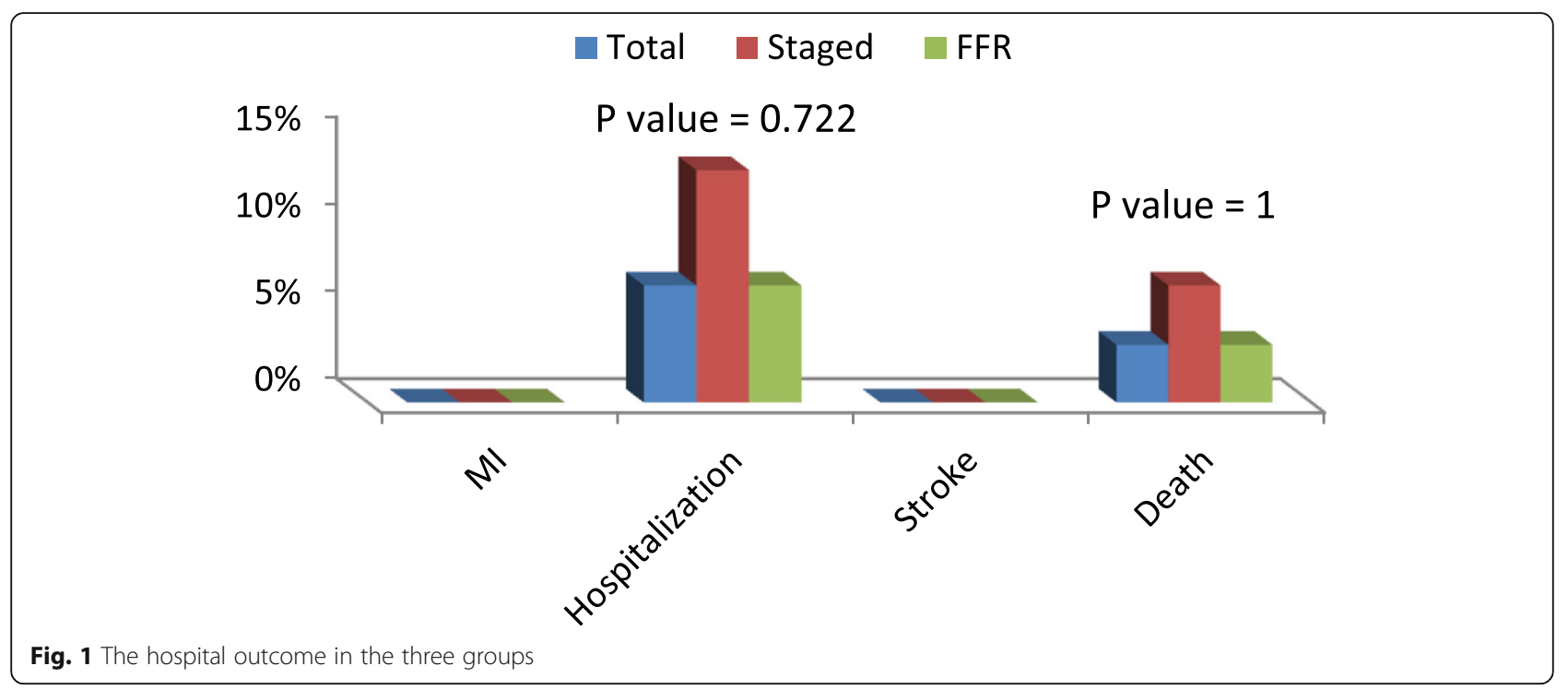

staged group; however, there was no statistically significant difference between the three groups ( $\mathrm{P}$ value = 0.805). The mean $\mathrm{EF}$ was comparable among the three groups ( $\mathrm{P}$ value $=0.546)$.

Regarding the angiographic criteria, the LAD was the most affected vessel among the three groups, and this was similar in the three groups. The mean value of the SYNTAX score was comparable between the three groups ( $\mathrm{P}$ value $=0.736$ )

Although multivessel disease was an inclusion criterion, however, the FFR changed the decision in 7 patients $(23.33 \%)$ who had only one vessel revascularized (hemodynamically significant lesion FFR $\leq 0.80$ ), and this difference was statistically significant $(P$ value $=0.001$ ). As shown in Table 2, there is no "one vessel" only revascularization in the total and staged groups (multivessel disease was an inclusion criterion); however, there were 29 patients that represents $96.63 \%$ of the total group patients who had two vessels revascularized and only one patient had three vessels revascularized. On the other hand, there were only two patients in the staged group who had a total of three vessels revascularized (all PCI settings). However, there were 23 patients in the FFR group who had twovessel revascularization (no patient had three-vessel revascularization in the FFR group).

Also, the total number of stents used was 73 and 72 in the total and the staged groups, respectively, compared to only 61 stents used in the FFR group. This difference was statistically significant ( $\mathrm{P}$ value $=<0.001$ ). The duration of the procedure and the volume of contrast used were the least in the staged group, which was statistically significant $(\mathrm{P}$ value $=<0.001)$.

There was only one patient who suffered renal impairment from the total group, and he was managed medically that did not require dialysis (Table 3). Also, there were 5 patients $(16.67 \%)$ from the staged group who experienced anginal pain during the hospital stay that was compared to 2 patients in the total group and only one patient in the FFR group. However, no in-stent thrombosis complication was encountered among the three

Table 1 The hospital outcome of the three groups. After the procedure was finished, the patient was put under observation for 35 days. There was only one patient who suffered renal impairment from the total group. Also, there were 5 patients from the staged group who experienced unstable angina during the hospital stay that was compared to 2 patients and only one patient in the total and FFR groups, respectively

\begin{tabular}{|c|c|c|c|c|c|c|c|}
\hline & \multicolumn{2}{|l|}{ Total } & \multicolumn{2}{|l|}{ Staged } & \multicolumn{2}{|l|}{ FFR } & \multirow{2}{*}{$\begin{array}{l}P \\
\text { value }\end{array}$} \\
\hline & No. of patients & $\%$ & No. of patients & $\%$ & No. of patients & $\%$ & \\
\hline $\mathrm{Ml}$ & 0 & $0.0 \%$ & 0 & $0.0 \%$ & 0 & $0.0 \%$ & - \\
\hline Hospitalization & 2 & $6.7 \%$ & 4 & $13.3 \%$ & 2 & $6.7 \%$ & 0.722 \\
\hline Stroke & 0 & $0.0 \%$ & 0 & $0.0 \%$ & 0 & $0.0 \%$ & - \\
\hline Death & 1 & $3.3 \%$ & 2 & $6.7 \%$ & 1 & $3.3 \%$ & 1 \\
\hline Total & 3 & $10 \%$ & 6 & $20 \%$ & 3 & $10 \%$ & 0.578 \\
\hline
\end{tabular}


Table 2 The short-term outcome of the three groups. After 6 months, there was an office- or/and telephone-based interview done with each patient to evaluate the short-term outcome of the management plan. Two patients in both the total and the FFR groups were hospitalized due to unstable angina, and this was compared to 4 patients in the staged group. The staged group had the greatest incidence of complication between the three groups as there were 6 patients (20\%) who suffered complications during this period

\begin{tabular}{|c|c|c|c|c|c|c|c|c|}
\hline & & \multicolumn{2}{|l|}{ Total } & \multicolumn{2}{|l|}{ Staged } & \multicolumn{2}{|l|}{ FFR } & \multirow{2}{*}{$\begin{array}{l}P \\
\text { value }\end{array}$} \\
\hline & & Count & Col \% & Count & $\%$ & Count & $\%$ & \\
\hline \multirow[t]{3}{*}{ Treated vessel } & Single vessel & 0 & $0 \%$ & 0 & $0 \%$ & 7 & $23.33 \%$ & 0.001 \\
\hline & Two vessels & 29 & $96.67 \%$ & 28 & $93.33 \%$ & 23 & $76.67 \%$ & 0.070 \\
\hline & Three vessels & 1 & $3.33 \%$ & 2 & $6.67 \%$ & 0 & $0 \%$ & 0.770 \\
\hline
\end{tabular}

groups (Fig. 2). Finally, the incidence of major adverse cardiac and cerebrovascular events was comparable among the three groups.

\section{NSTEMI versus unstable angina}

Twenty-six of our patients had elevated troponin (NSTE $\mathrm{MI})$, and 64 were diagnosed as (UA) patients.

Eight NSTEMI patients were in the total revascularization group, 8 NSTEMI patients were in the FFR guided revascularization group, and 10 NSTEMI patients were in the staged revascularization group.

We found no statistically significant difference between the three groups in the distribution of NSTEMI and UA ( $\mathrm{p}=\mathrm{NS})$.

Also, there was no statistically significant impact on the outcomes of patients $(\mathrm{p}=\mathrm{NS})$.

\section{Discussion}

The main finding of our study is that in NSTEACS patients with multivessel disease, coronary revascularization strategies (total, staged, or FFR guided) are comparable regarding immediate and short-term (6 months) clinical follow-up.

We included ninety patients in our study who presented to the ER with NSTEACS in our hospital, in an 8 -month period. Being performed in a military medical

Table 3 Short-term complications. There was only one patient who suffered renal impairment from the total group. Also, there were 5 patients (16.67\%) from the staged group who experienced anginal pain during the hospital stay that was compared to 2 patients in the total group and only one patient in the FFR group

\begin{tabular}{|c|c|c|c|c|c|c|c|}
\hline & \multicolumn{2}{|c|}{ Total } & \multicolumn{2}{|c|}{ Staged } & \multicolumn{2}{|l|}{ FFR } & \multirow{2}{*}{$\begin{array}{l}P \\
\text { value }\end{array}$} \\
\hline & No. & Col \% & No. & $\%$ & No. & $\%$ & \\
\hline In-stent thrombosis & 0 & $0.0 \%$ & 0 & $0.0 \%$ & 0 & $0 \%$ & - \\
\hline Renal impairment & 1 & $3.3 \%$ & 0 & $0.0 \%$ & 0 & $0 \%$ & 1 \\
\hline Unstable angina & 2 & $6.67 \%$ & 5 & $16.67 \%$ & 1 & $3.33 \%$ & 0.263 \\
\hline Total & 3 & $10 \%$ & 5 & $16.67 \%$ & 1 & $3.33 \%$ & 0.284 \\
\hline
\end{tabular}

hospital may explain the predominance of the male gender among the study population. The similarity of basic characteristics and laboratory findings of patients in the three groups (regarding demographic criteria, risk factors, clinical presentation, ECG, echocardiography, laboratory, and angiographic findings) allows for a better comparison among the three groups.

Indeed, our study protocol was similar to the FAMOUS-NSTEMI trial, which found that FFR disclosure resulted in a change in the treatment plan of 144 patients planned for PCI. After applying FFR, only 117 patients underwent PCI [8]. This could be explained by the fact that measuring FFR changes the classification of stenosis from "significant stenosis" for PCI to "non-significant stenosis" managed by only optimal medical treatment. In agreement with the results of the FAME trial, we found that significantly less stents per patient were placed in the FFR group than in the other groups [9]. Furthermore, the 2-year follow-up of the FAME Study found that the number of stents used was $2.7 \pm$ 1.2 in the angiography-guided group and $1.9 \pm 1.3$ in the FFR-guided group ( $\mathrm{p}<0.001)$ [10]. This is explained simply due to less number of lesions indicated for PCI after measuring FFR.

Our study found that the volume of contrast used was least in the staged group than that used in the total and FFR groups. In agreement with our results, the "CvLPRIT" trial demonstrated that total contrast used was 250 (190-330) $\mathrm{ml}$ in the "complete revascularization group" versus $190(150-250) \mathrm{ml}$ in the "infarct-related artery (IRA)-only revascularization group" (P value < $0.0001)$ [6].

Regarding the mean procedure, we found that duration was least in the staged group than in the total and FFR groups. Similarly, in the CVLPRIT trial, the total procedure time was 55 (38-74) min in the "complete" revascularization group, while in the "infarct-related artery (IRA)-only revascularization group," it was 41 (30-55.5) min (P value $<0.0001$ ) [6]. This can be explained by the fact that in the staged group, the duration of the procedure and volume of contrast needed to deploy stent(s) in only one vessel are significantly lower than that needed to fix all stenosed 


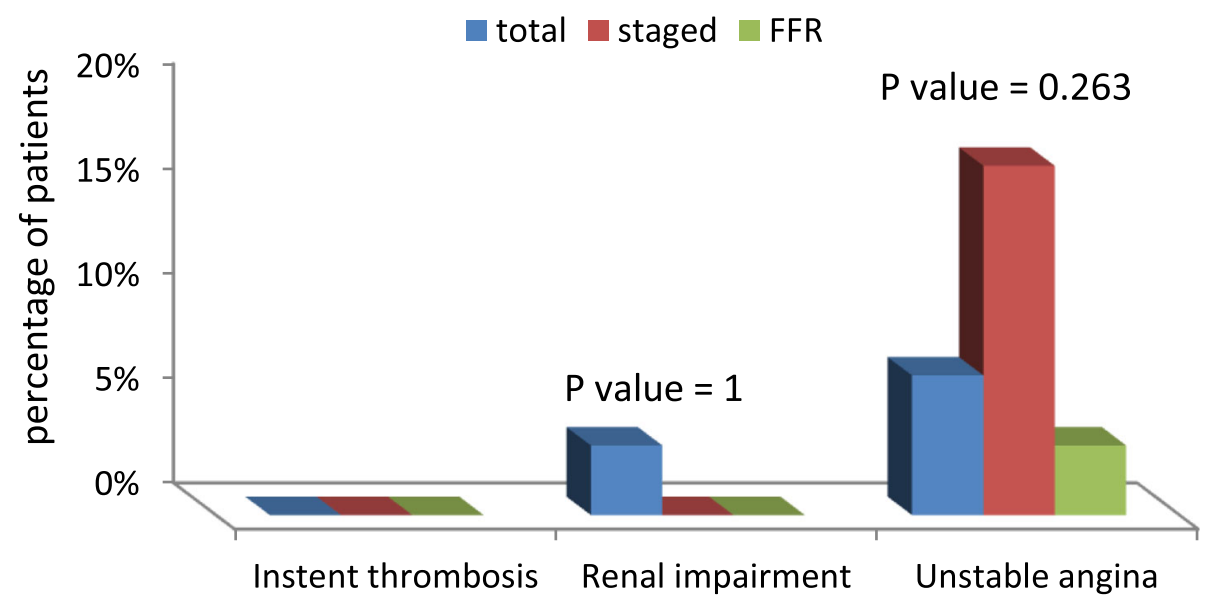

Fig. 2 The short-term outcome in the three groups

vessels in the total group or all the functionally significant lesions in the FFR group.

Regarding the procedure outcome, our study found that there was no statistically significant difference between the three groups. In concordance with our results, the FAMOUS-NSTEMI trial found that in-hospital adverse events were similar in the "FFR-disclosure group" and "angiography group" [8]. Also, the "CvLPRIT trial" found that the periprocedural events and ischemia testing were similar in the complete revascularization and IRA-only revascularization groups [6]. In contrast to our results, the "FAME Study" found that hospital stay at baseline admission was significantly more in the angiography group than that in the FFR group [10].

We found that major acute cerebrovascular and cardiac events were comparable among the three groups at the 6-month follow-up. In agreement with our results, the FAMOUS-NSTEMI trial found that 14 (8.0\%) of 176 patients in the "FFR-guided group" and 15 (8.6\%) of 174 in the "angiography-guided group" experienced cardiac death, non-fatal myocardial infarction, or heart failure hospitalization $(\mathrm{P}=0.89)$. Myocardial infarction relating to revascularization occurred in $5(2.8 \%)$ patients in the "FFR-guided group" and 11 (6.3\%) patients in the "angiography-guided group" ( $P=0.12)$. Major adverse cardiac events excluding MI related to revascularization occurred in 10 (5.7\%) patients in the "FFR-guided group" and $5(2.9 \%)$ patients in the "angiography-guided group" $(\mathrm{P}=0.25)$ [8]. Also supporting our results, the FAME Study showed that all-cause mortality at 2 years was $3.8 \%(\mathrm{n}=19)$ in the angiography-guided group and $2.6 \%$ $(\mathrm{n}=13)$ in the FFR-guided group $(\mathrm{p}=0.25)$. After 2 years, MACE had occurred in 111 patients $(22.4 \%)$ in the angiography-guided group and in 91 patients (17.9\%) in the FFR group $(p=0.08)$ [10]. According to the results of our study, there was no statistically significant difference between the three groups in the hospital outcome or in the short-term outcome.

In contrast to our results, the major findings of "SMILE trial" were as follows: "one-stage" complete coronary revascularization is superior to "multistage" complete coronary revascularization in terms of MACE [7]. Similarly, the "CvLPRIT trial" found that MACE was significantly lower in the complete revascularization arm $(10.0 \%)$ than in the IRA-only arm (21.2\%) [6]. Another study observed that complete coronary revascularization is associated with a lower rate of the composite endpoint (death, myocardial infarction, or revascularization) [11].

Interestingly, we found that the FFR-guided approach resulted in changes in stenosis classification and patient management in $23.33 \%(n=7)$ of the FFR group patients. The rate of coronary revascularization was reduced at the index procedure, and this difference was maintained at 6 months.

Finally, we believe that a larger and longer study may be necessary to properly assess the differences between the three management plans regarding health outcomes and cost-effectiveness.

\section{Limitations}

A small sample size that is limited only to a single center was the most prominent limitation. A short-term followup period was implemented; however, a longer period is needed to detect all possible health care outcomes. A cost-benefit study of each management plan was not performed, which may help to set management policies in developing countries with limited resources.

\section{Conclusion}

Considering NSTEACS patients with multivessel disease, different coronary revascularization strategies (total, staged, or FFR) are comparable regarding immediate and 
short-term (6 months) clinical follow-up. FFR can change the preplanned management, and less number of stents per patient is needed when FFR is utilized. We believe that a larger study with a longer follow-up period is needed to determine the optimal strategy for NSTEACS patients with multivessel disease.

\section{Abbreviations}

CABG: Coronary artery bypass surgery; FFR: Fractional flow reserve; IRA: Infarct-related artery; LAD: Left anterior descending; NS: Not significant; NSTEACS: Non-ST segment elevation acute coronary syndrome; $\mathrm{PCl}$ : Percutaneous coronary intervention

\section{Acknowledgements}

Not applicable

\section{Declarations}

\section{Authors' contributions}

A.O.E, M.A, R.D, A.E, and A.A.E analyzed and interpreted the patient data and were major contributors in writing the manuscript. All authors read and approved the final manuscript.

\section{Funding}

None

\section{Availability of data and materials}

All data generated or analyzed during this study are included in this published article.

\section{Ethics approval and consent to participate}

Ethics approval was obtained from the Ethics Committee of the Cardiology Department at Cairo University (CU-2018-23). All patients provided written consent to participate.

\section{Consent for publication}

Not applicable

\section{Competing interests}

The authors declare that they have no competing interests.

\section{Author details}

${ }^{1}$ Cardiology Department, Kobry El-kobba Military Medical Hospital, Cairo, Egypt. ${ }^{2}$ Cardiovascular Department, Kasr-Alainy Hospital, Cairo University, 1 Saraya St., Third Floor, Manial, Cairo, Egypt.

Received: 7 April 2021 Accepted: 5 June 2021

Published online: 26 June 2021

\section{References}

1. Muller DW, Topol EJ, Ellis SG, Sigmon KN, Lee K, Califf RM, for the Thrombolysis and Angioplasty in Myocardial Infarction (TAMI) Study Group (1991) Multivessel coronary artery disease: a key predictor of short-term prognosis after reperfusion therapy for acute myocardial infarction. Am Heart J 121(4):1042-1049. https://doi.org/10.1016/0002-8703(91)90661-Z

2. Toma M, Buller CE, Westerhout CM, Fu Y, O'Neill WW, Holmes DR, Hamm CW, Granger CB, Armstrong PW, for the APEX-AMI Investigators (2010) Nonculprit coronary artery percutaneous coronary intervention during acute STsegment elevation myocardial infarction: insights from the APEX-AMI trial. Eur Heart J 31(14):1701-1707. https://doi.org/10.1093/eurheartj/ehq129

3. Cavender MA, Milford-Beland S, Roe MT, Peterson ED, Weintraub WS, Rao SV (2009) Prevalence, predictors, and in-hospital outcomes of non-infarct artery intervention during primary percutaneous coronary intervention for STsegment elevation myocardial infarction (from the National Cardiovascular Data Registry). Am J Cardiol 104(4):507-513. https://doi.org/10.1016/j.amjca rd.2009.04.016

4. Hannan EL, Samadashvili Z, Walford G, Holmes DR Jr, Jacobs AK, Stamato NJ, Venditti FJ, Sharma S, King SB III (2010) Culprit vessel percutaneous coronary intervention versus multivessel and staged percutaneous coronary intervention for ST-segment elevation myocardial infarction patients with multivessel disease. J Am Coll Cardiol Intv 3(1):22-31. https://doi.org/10.101 6/j.jcin.2009.10.017

5. Wald DS, Morris JK, Wald NJ, Chase AJ, Edwards RJ, Hughes LO, Berry C, Oldroyd KG, for the PRAMI Investigators (2013) Randomized trial of preventive angioplasty in myocardial infarction. N Engl J Med 369(12):11151123. https://doi.org/10.1056/NEJMoa1305520

6. Gershlick AH, Khan JN, Kelly DJ, Greenwood JP, Sasikaran T, Curzen N, Blackman DJ, Dalby M, Fairbrother KL, Banya W, Wang D, Flather M, Hetherington SL, Kelion AD, Talwar S, Gunning M, Hall R, Swanton H, McCann GP (2015) Randomized trial of complete versus lesion-only revascularization in patients undergoing primary percutaneous coronary intervention for STEMI and multivessel disease: the CvLPRIT trial. J Am Coll Cardiol 65(10):963-972. https://doi.org/10.1016/j.jacc.2014.12.038

7. Sardella G, Lucisano L, Garbo R, Pennacchi M, Cavallo E, Stio RE, Calcagno S, Ugo F, Boccuzzi G, Fedele F, Mancone M (2016) Single staged compared with multi-staged $\mathrm{PCl}$ in multivessel NSTEMI patients. J Am Coll Cardiol. 67(3):264-272. https://doi.org/10.1016/j.jacc.2015.10.082

8. Layland J, Oldroyd KG, Curzen N, Sood A, Balachandran K, Das R, Junejo S, Ahmed N, Lee MM, Shaukat A, O'Donnell A, Nam J, Briggs A, Henderson R, McConnachie A, Berry C, FAMOUS-NSTEMI investigators (2015) Fractional flow reserve vs. angiography in guiding management to optimize outcomes in non-ST-segment elevation myocardial infarction: the British Heart Foundation FAMOUS-NSTEMI randomized trial. Eur Heart J. 36(2):100111. https://doi.org/10.1093/eurheartj/ehu338

9. Tonino PA, De Bruyne B, Pijls NH, Siebert U, Ikeno F, van't Veer M, Klauss V, Manoharan G, Engstrøm T, Oldroyd KG, Ver Lee PN, MacCarthy PA, Fearon WF, FAME Study Investigators (2009) Fractional flow reserve versus angiography for guiding percutaneous coronary intervention. N Engl J Med 360(3):213-224. https://doi.org/10.1056/NEJMoa0807611

10. Pijls NH, Fearon WF, Tonino PA, Siebert U, Ikeno F, Bornschein B, van't Veer $M$, Klauss V, Manoharan G, Engstrøm T, Oldroyd KG, ver Lee P, MacCarthy P, de Bruyne B, FAME Study Investigators (2010) Fractional flow reserve versus angiography for guiding percutaneous coronary intervention in patients with multivessel coronary artery disease: 2-year follow-up of the FAME (Fractional Flow Reserve Versus Angiography for Multivessel Evaluation) study. J Am Coll Cardiol 56(3):177-184. https://doi.org/10.1016/j.jacc.2010.04.012

11. Shishehbor MH, Lauer MS, Singh IM, Chew DP, Karha J, Brener SJ, Moliterno DJ, Ellis SG, Topol EJ, Bhatt DL (2007) In unstable or non-ST-segment acute coronary syndrome, should patients with multivessel coronary artery disease undergo multivessel or culprit-only stenting? J Am Coll Cardiol 49(8):849854. https://doi.org/10.1016/j.jacc.2006.10.054

\section{Publisher's Note}

Springer Nature remains neutral with regard to jurisdictional claims in published maps and institutional affiliations.

\section{Submit your manuscript to a SpringerOpen ${ }^{\circ}$ journal and benefit from:}

- Convenient online submission

- Rigorous peer review

- Open access: articles freely available online

- High visibility within the field

- Retaining the copyright to your article

Submit your next manuscript at $\boldsymbol{\nabla}$ springeropen.com 